\title{
Psicologia e Arquitetura: Como a Einfuihlung e a Gestalt atuam nos ambientes
}

\author{
Mauricio Dallastra ${ }^{1}$; Caroline Ogura ${ }^{2}$; Bruna Gazzoni ${ }^{3}$; \\ Luiz Eduardo Brescovit ${ }^{4}$; Bruna Lopes Costa ${ }^{5}$
}

\begin{abstract}
Resumo: O presente artigo tem como objetivo expor a importância do conhecimento sobre como as formas e a disposição dos elementos que estão ao redor podem interferir no cotidiano e na maneira como os indivíduos percebem o ambiente. Para tanto adotou-se as teorias de einfühlung e os princípios da Gestalt. O artigo foi elaborado tendo como metodologia pesquisa em referências bibliográficas e estudos relacionados tanto à arquitetura quando à psicologia e a relação intrínseca entre ambas. Diante do interesse dos autores, houve o aprofundamento em leituras para que as informações pudessem levantar questões pertinentes quanto à relação da arquitetura no cotidiano das pessoas e como a psicologia se faz presente em ambientes projetados. Como resultado, concluiu-se que as formas e os elementos arquitetônicos são instrumentos capazes de promover sensações e emoções, mesmo que de forma subconsciente, afirmando, desta forma, a intrínseca relação entre o ramo da arquitetura com a psicologia.
\end{abstract}

Palavras-chave: Psicologia ambiental. Einfühlung. Gestalt.

\section{Psychology and Architecture: How Einfühlung and Gestalt work in environments}

\begin{abstract}
This article aims to expose the importance of knowledge about how the forms and the disposition of the elements that are around can interfere in the daily life and the way in which the individuals perceive the environment. For that, the theories of einfühlung and the principles of Gestalt were adopted. The article was elaborated having as research methodology in bibliographical references and studies related to architecture as well as to psychology and the intrinsic relation between both. In the interest of the authors, there was a deepening of readings so that the information could raise pertinent questions about the relation of the architecture in the daily life of the people and how the psychology is present in projected environments. As a result, it was concluded that architectural forms and elements are instruments capable of promoting sensations and emotions, even in a subconscious way, thus asserting the intrinsic relationship between the branch of architecture and psychology.
\end{abstract}

Keywords: Environmental psychology. Einfühlung. Gestalt.

\footnotetext{
${ }^{1}$ Arquiteto e Urbanista graduado pela Universidade Paranaense, no ano de 2012 e especialista em Iluminação e Design de Interiores pelo Instituto de Pós Graduação IPOG no ano de 2016. Contato: mauriciodallastra@ hotmail.com.

${ }^{2}$ Arquiteta e Urbanista pela Universidade do Estado de Mato Grosso no ano de 2011.

${ }^{3}$ Arquiteta e Urbanista pela Universidade do Estado de Mato Grosso no ano de 2016.

${ }^{4}$ Professor graduado em Educação Física Bacharelado e Licenciatura pela Faculdade Assis Gurgacz no ano de 2009, com especialização em Educação Infantil e anos iniciais no ano de 2009, Pedagogo pela Faculdade FAEST, no ano de 2016.

${ }^{5}$ Arquiteta e Urbanista pela Universidade do Estado de Mato Grosso no ano de 2016.

658 Id on Line Rev. Mult. Psic. V.12, N. 39. 2018 - ISSN 1981-1179

658 Edição eletrônica em http://idonline.emnuvens.com.br/id
} 


\section{Introdução}

A elaboração de construções vai além do simples projetar quando se leva em consideração o indivíduo que estará inserido naquele contexto. Dessa forma, o presente artigo tem por finalidade levantar questões relacionadas a como determinados espaços e/ou ambientes são interpretados pelo usuário de acordo com sua forma e, consequentemente, o papel da psicologia quando aliada à arquitetura.

A proposta é iniciar questionamentos a respeito da relação intrínseca da arquitetura aliada à psicologia, e como a psicologia ambiental pode moldar o espaço e a percepção espacial dos indivíduos. Desta forma, espera-se que esta pesquisa instigue e possibilite novos trabalhos acerca desta temática.

Para a elaboração da pesquisa foram feitas leituras aprofundadas de referências bibliográficas voltadas à área da arquitetura e psicologia e em especial sobre a psicologia ambiental.

\section{A arquitetura}

Arquiteto; tecton, em grego, significa um artífice, o qual constrói elementos a partir da junção de peças, tal qual um carpinteiro, e não como um escultor; arqui indica superioridade, logo arquitecton quer dizer "grande carpinteiro". (COLIN, 2000).

Antes do surgimento da escrita, a história do homem divide-se em quatro partes: pedra lascada, pedra polida, paleolítico e neolítico. Foi somente durante o período neolítico que surgiram os primeiros indícios de um conhecimento arquitetônico. Neste, os primeiros homo sapiens deixaram de buscar abrigo em cavernas e passaram a edificar sua própria moradia, dominando a ciência da agronomia e demonstrando, portanto, o que seria então as primeiras expressões do conhecimento arquitetônico. (STRICKLAND, 2003).

De acordo com Silvio Colin (2000), não há registros específicos a respeito da arquitetura ou das artes plásticas, antes do início do Império Romano, quando Marcus Vitruvius Pollio escreve uma série de Dez livros sobre arquitetura determinando, além de outras considerações a respeito da temática, os sistemas da arquitetura, defendendo que a 
mesma deve apresentar três pontos básicos: firmitas, utilitas, venustas, que, traduzidos, significam respectivamente solidez, utilidade e beleza. (COLIN, 2000).

Vitrúvius e seus escritos são um relevante marco da arquitetura, pois estes inspiraram diversos tratados a partir do Renascimento até o século XIX, e suas postulações ainda são observadas

Arquitetura trata-se, nos dias hodiernos, de uma profissão de nível superior, amparada pela lei $\mathrm{n}^{\circ} 12.378$, de 31 de dezembro de 2010, que abrange conhecimentos nas áreas humanas, técnicas e artísticas; de um produto cultural, considerando a sua importância histórica, a qual contribui para compreensão do modo de vida das civilizações antepassadas; e uma arte, no ponto de vista estético, com a qual está intrinsicamente relacionada. (COLIN, 2000)

De acordo com o autor mencionado acima, a arquitetura é uma arte, porém, diferenciada das demais conhecidas atualmente. É claro que apresenta semelhanças, como por exemplo, com a pintura e escultura, com as quais se utiliza de matéria similar - luz, sombra, cores, figuras, entre outros, no entanto se difere, pois, sua função prática antecede a estética, sendo a arquitetura pensada inicialmente na solidez estrutural e na estanqueidade de paredes, deixando em segundo plano o valor estético. Além disto, a arquitetura é uma arte inevitável e apresenta contato obrigatório com as pessoas, ao contrário de outras artes. Uma pessoa, ao ver um filme que não lhe está agradando pode, simplesmente, desligá-lo e não vê-lo, enquanto que a arquitetura é elemento fundamental de um cenário no qual a vida acontece e, portanto, não é possível ignorá-la.

Assim como as mais variadas formas de arte, a arquitetura detém o poder de transmitir sensações através das formas, volumes e cores e influenciam diretamente no conforto e bem estar do usuário. Pode-se, através da arte, promover as mais variadas emoções àqueles que as experimentam.

O arquiteto finlandês Pallasmaa (2005 apud MARTAU, 2007) pondera que a arquitetura que estima a vida deve atender a todos os sentidos simultaneamente e fundir a nossa autoimagem com a nossa experiência de mundo, tendo como tarefa mental a acomodação e a integração, articulando as experiências de estar no mundo e aumentando nosso senso de realidade e de si mesmo. A dimensão da escala arquitetônica e sua compreensão implicam a medição inconsciente do objeto ou do edifício com o corpo e a projeção do esquema corporal individual no espaço em questão. 
No século XX os autores teóricos da arquitetura de alguma forma consideraram para o conceito espaço, significados mais voltados para o conceito aristotélico. Entretanto, nos últimos 30 anos, com uma abordagem cada vez mais interdisciplinar, o termo Ambiente começa a ser melhor apresentado. Um entendimento que inclui o homem, onde, mesmo de forma passiva, cada pessoa presente em um local contribui para o que está acontecendo. Pessoas são componentes daquilo que está acontecendo, envolvidas em um sistema social (RIVLIN, 2003). Como o prof. Günther (2003) sugere, mais especificamente, reservar o adjetivo ambiente para tratar da relação recíproca entre indivíduo e espaço, e esta relação encontra embasamento teórico na psicologia.

\section{Psicologia Ambiental e o espaço}

Os trabalhos em psicologia, que relacionam estudos dos espaços construídos e sua influência sobre o comportamento humano, foram associados ao termo 'psicologia arquitetural'. Alguns trabalhos desta área partiram de estudos realizados nos anos $60 \mathrm{em}$ setores psiquiátricos de hospitais. Mais recentemente esta área de conhecimento ganha sentido mais amplo, não apenas relacionado ao ambiente edificado, no entanto, suas discussões ganharam mais aprofundamento. Esta área ganha a nomenclatura de Psicologia Ambiental, ainda que com algumas ressalvas sobre o termo. A Psicologia Ambiental é o estudo da transação entre indivíduos e o cenário físico (GIFFORD, 1997 Apud GÜNTHER, 2003). O objetivo destas transações recai na inter-relação e interdependência pessoa-ambiente, conceitualmente distinto da ação isolada de seus componentes sobre o comportamento (PINHEIRO,1997).

Gifford (1997 apud GÜNTHER, 2003) afirma que indivíduos modificam o ambiente e seu comportamento e experiências são modificados pelo ambiente. Para tanto, são levados em conta três elementos básicos da Psicologia Ambiental: o comportamento e experiência humanos; espaço (ou cenário) físico; e por último, a ligação recíproca entre os dois primeiros. Primeiramente, o comportamento e experiência constituem a figura, contra o fundo do espaço físico e posteriormente, o espaço constitui a figura, contra o fundo de comportamento e experiência.

É importante ressaltar que o ciclo psicológico das pessoas nos ambientes inicia-se com a percepção, no qual Pinheiro (1997) salienta que na percepção ambiental o participante 
é parte da cena percebida, se desloca por ela, tendo múltiplas perspectivas, quando seus interesses e objetivos são transformados em partes ativas da observação.

Segundo Vernon (1974), o indivíduo constrói seu mundo percebido de acordo com a manutenção de máxima estabilidade, permanência e coerência. A estreita relação entre percepção e sensação é notória e fundamental para que os indivíduos entendam que as sensações obtidas em determinados lugares provém de diversas fontes, sejam suas experiências ou das intenções projetivas das formas encontradas nos locais.

\section{Psicologia aliada a arquitetura}

A arquitetura apresenta forte relação com a psicologia, desde a sua concepção até a forma como é interpretada pelas pessoas, remetendo-as às mais diversas sensações. $\mathrm{O}$ termo psique, em grego, significa alma. $\mathrm{O}$ "estudo da alma" é uma ciência recente, datada do século XIX. Na arquitetura, a aplicação e estudo da abordagem psicológica iniciam-se com Robert Vischer e a teoria de einfühlung, já se mostra presente desde os primórdios, principalmente nos edifícios de cunho religioso, como nas catedrais góticas. (COLIN, 2000). Outra teoria é a da Gestalt, que faz menção às formas dos objetos no espaço e como isso é sentido pelos indivíduos no meio.

\section{Einfühlung}

Einfühlung traduz-se por empatia, que significa "projeção imaginária ou mental de um estado subjetivo, quer afetivo, quer conato ou cognitivo, nos elementos de uma obra de arte ou de um objeto natural, de modo que estes parecem imbuídos dele”. (MICHAELIS, 2009). Empatia significa afinidade com identificação. Entende-se, portanto, que um objeto estético possui as emoções e sentimentos de seu criador, tendo a capacidade de comunicar-se com terceiros. (COLIN, 2000) O observador projeta-se dentro do objeto, sentindo-se parte dele, e assim, desenvolve as suas próprias sensações de acordo com aquilo que visualiza, humanizando-as.

Alguns elementos geométricos, constantemente encontrados na arquitetura, são capazes de transmitir tais sensações, como explica o autor Zevi (2002): 
- A linha horizontal remete à essência, ao racional e ao intelectual. Está associada de tal forma devido à associação com o paralelismo da terra, sobre a qual o homem transita.

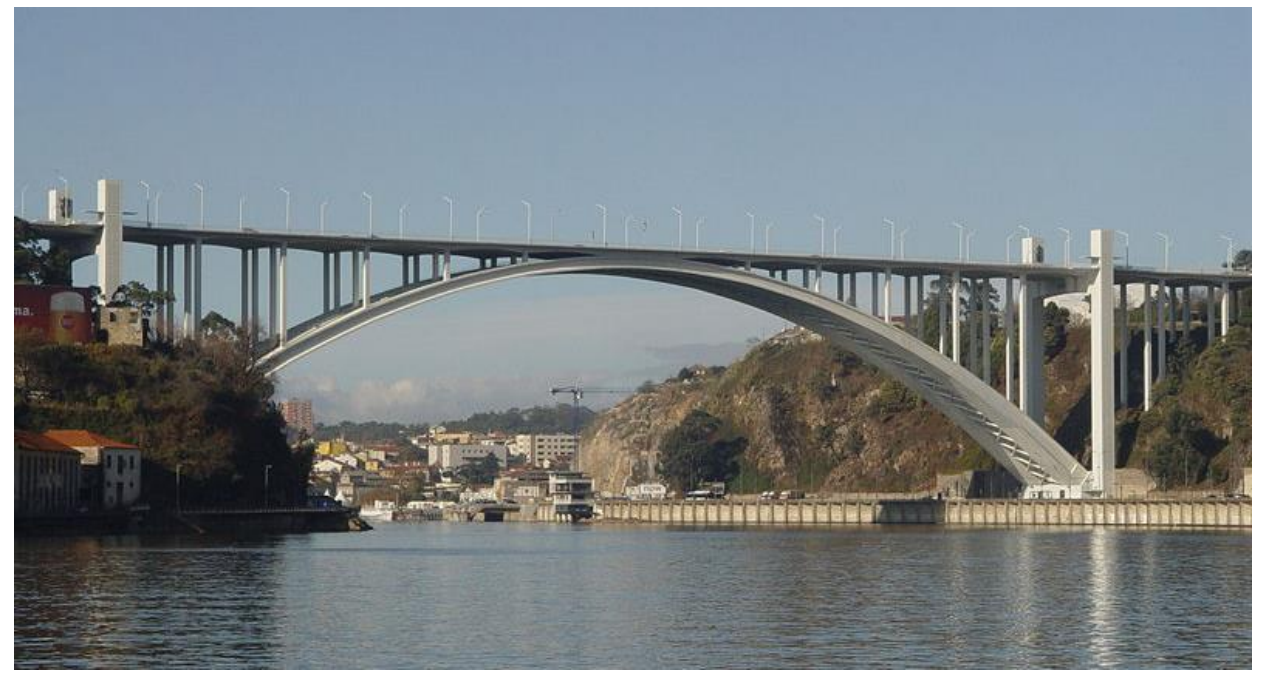

Figura 01: Ponte da Arrabida, Porto - Portugal

Fonte: Wikimedia,org, 2007

- A linha vertical simboliza o infinito, remetendo a visão do observador ao céu, desviando o olhar da sua diretriz normal. Esta representação é comum nas catedrais góticas, cujo período é marcado pela religiosidade, demonstrando imponência e harmonia divina. (BENUTTI, 2011). 


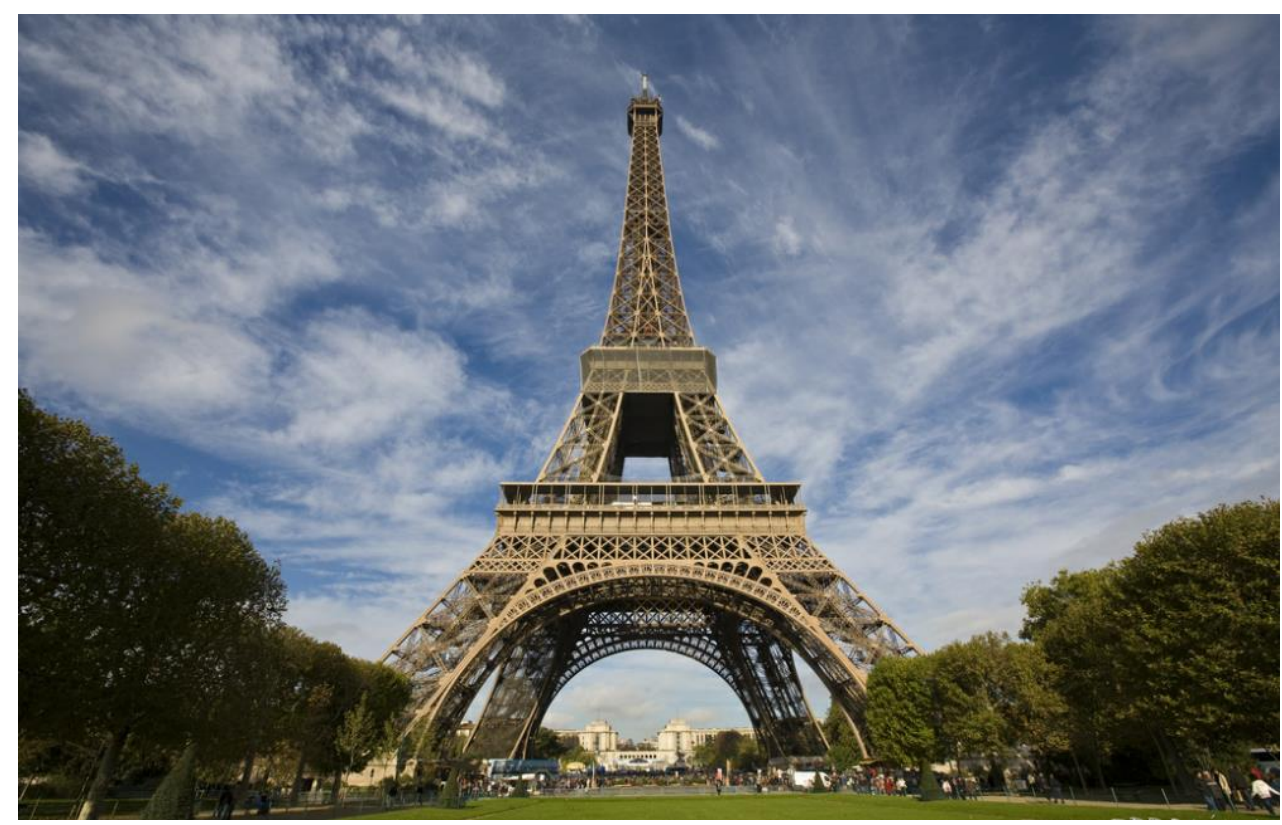

Figura 02: Torre Eiffel, Paris

Fonte: Ruy Barbosa Pinto, 2009

- A linha diagonal é a síntese e união das anteriores.



Figura 03: Puente de la Mujer Bridge, Buenos Aires - Argentina

Fonte: Calatrava, 2012

- Linhas retas significam certeza, firmeza e força. Esta não apresenta um ponto inicial nem final, sendo um trajeto eterno, com uma única direção. 
- As linhas curvas remetem à decoração, flexibilidade, e simbolizam o feminino. Neste caso há a possibilidade de encontrar o seu ponto inicial, formando uma circunferência, que é a representação do todo.

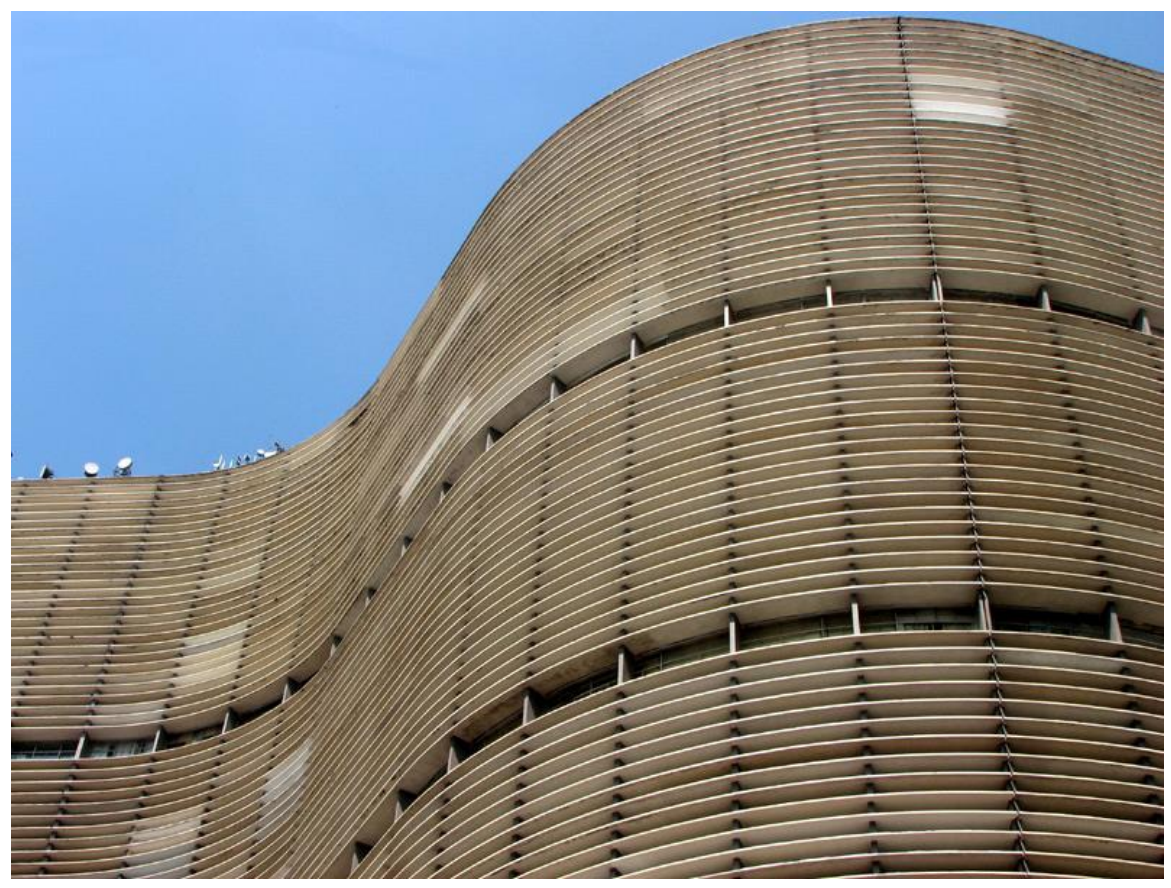

Figura 04: Edifício Copan, São Paulo - SP

Fonte: Sampaonline, 2012

- O cubo simboliza a integridade e segurança, por apresentar dimensões idênticas em todas as faces. 


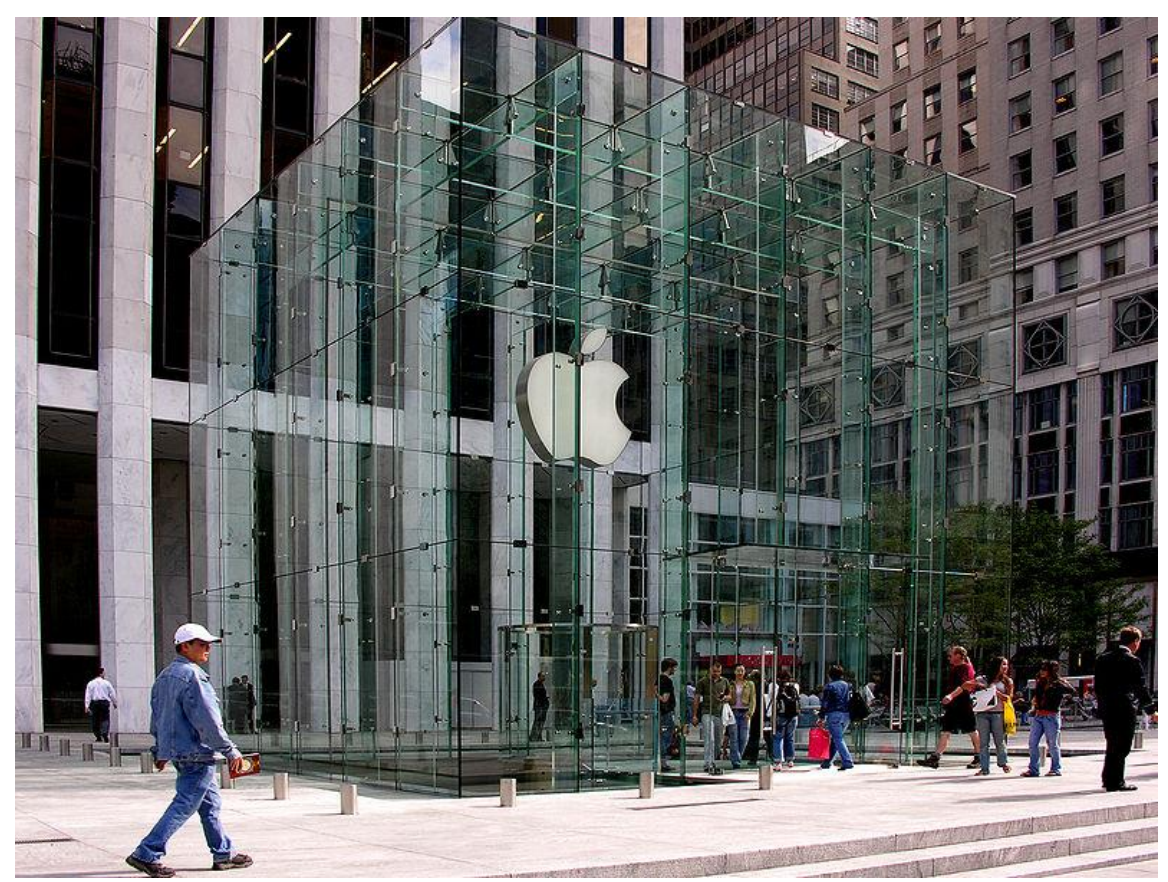

Figura 05: Apple Store, 15 $^{\text {th }}$ Avenue - NY

Fonte: Wikimedia.org, 2006

- O círculo representa equilíbrio, o controle a respeito de todos os elementos da vida.

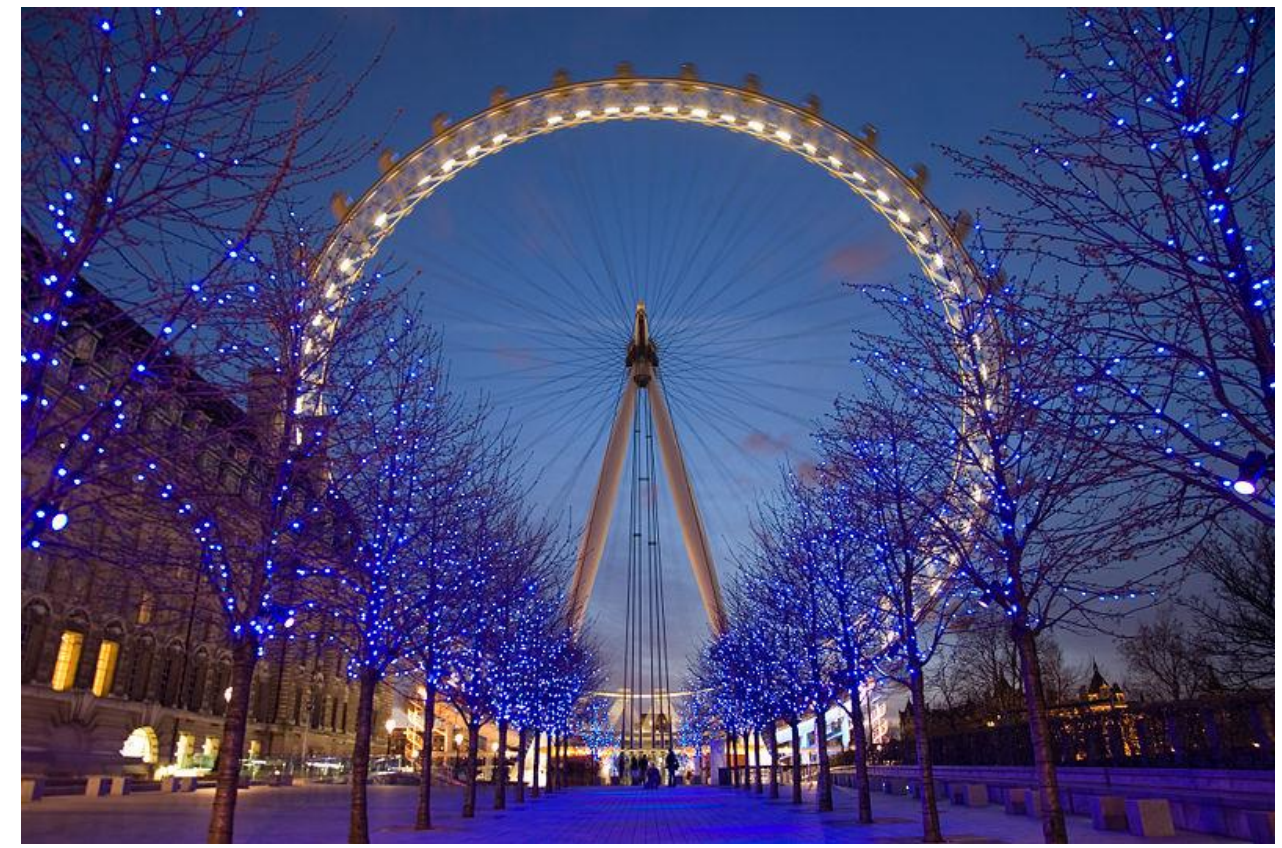

Figura 06: London Eye, Londres - UK

Fonte: Wikimedia, 2006 
- A elipse simboliza o movimento e inquietude, prendendo a atenção do observador aos dois pontos centrais, sem permitir que a vista repouse.

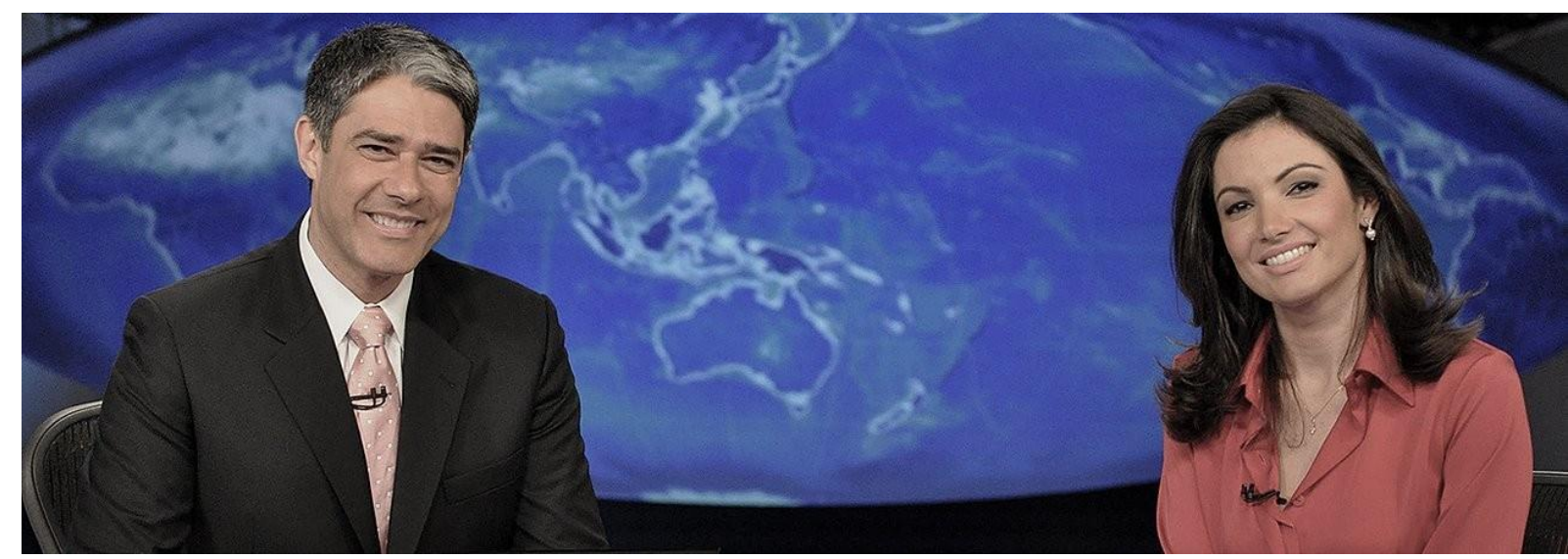

Figura 07: Jornal Nacional

Fonte: Globo.tv, 2012

- A esfera representa a perfeição, conclusão. Está associada às semiesferas encontradas nas basílicas.



Figura 08: Epcot Spaceship Earth, Walt Disney World, Orlando

Fonte: Wikimedia.org, 2010 
Sendo assim, a teoria de Einfühlung define que a emoção artística consiste na identificação do expectador com as formas, e por isso no fato da arquitetura transcrever os estados de espírito nas formas da construção, humanizando-as. (FISHER,1987).

\section{Gestalt}

Outra teoria apropriada para a proposta de estudo é a Gestalt, também conhecida como psicologia da forma, defende que objetos agrupados em um todo são diferentes do que a simples soma de suas partes, sendo interpretados por inteiro. Seus principais precursores são os psicólogos Max Wertheimer, Wolfgang Köhler e Kurt Koffka. Por meio de inúmeras pesquisas, a teoria da Gestalt vem para responder ao porquê de algumas formas agradarem mais do que outras. (FILHO, 2004).

Na prática da teoria da Gestalt, destaca-se a realização de um conjunto de exercício sensório-motores (que trabalham as áreas sensoriais e motoras do nosso corpo) e meditativos (de relaxamento). Estes exercícios pretendem, principalmente, que os indivíduos descubram novas forças existentes em si, para poderem ultrapassar as suas dificuldades (KOFFKA, 1975).

A figura abaixo demonstra a diferença entre um objeto, quando observado com as suas partes separadas e o outro como um conjunto de peças que formam um único objeto, neste caso, representado pela mesa.

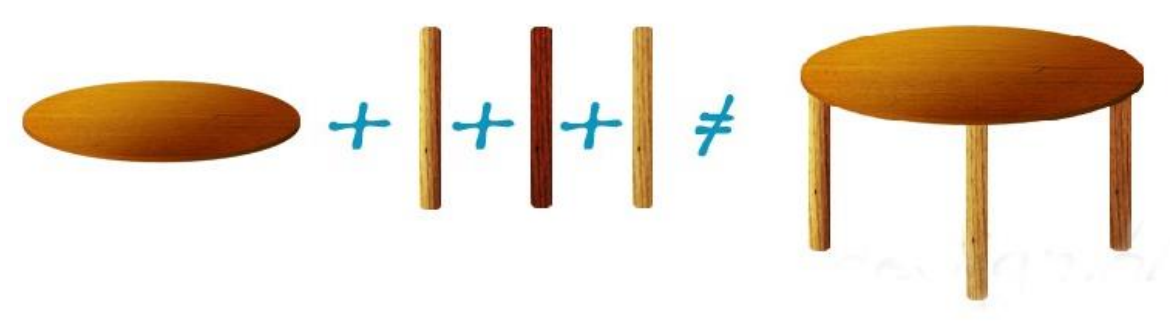

Figura 09: Exemplo explicativo da teoria da Gestalt

Fonte: Design.blog, 2009

De acordo com a teoria gestaltiana, o cérebro humano interpreta os objetos como um conjunto, e preenche automaticamente as partes faltantes, assim como no exemplo a seguir: 

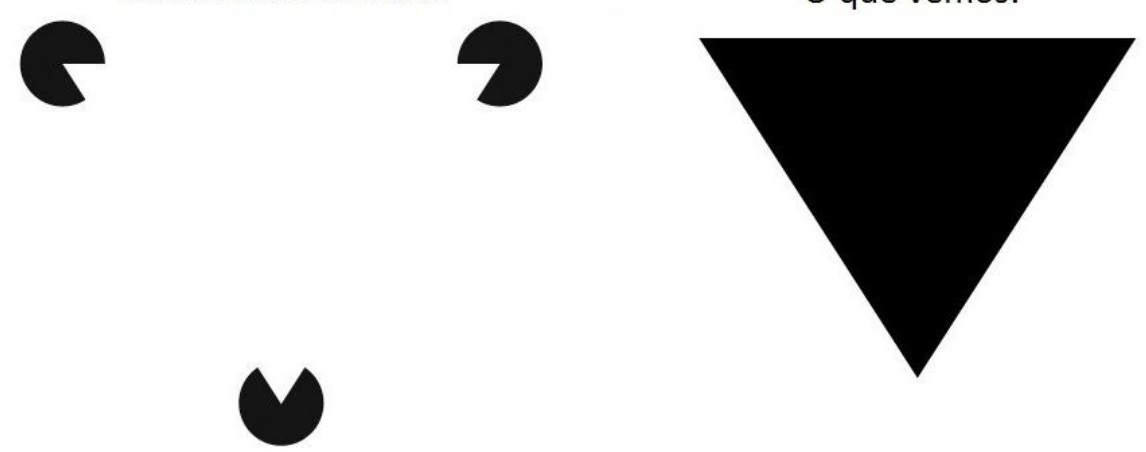

Figura 10: Exemplo explicativo da interpretação visual de acordo com as leis da Gestalt

Fonte: Design.blog, 2009

A Gestalt está dividida em 8 leis que se referem a interpretação e análise da forma do objeto, de acordo com Gomes Filho (2004):

Unidade: interpretada como um único elemento, que se encerra em si mesmo.

Segregação: significa a capacidade de percepção na qual o observador separa, identifica, evidencia ou destaca formas em um todo. É o elemento que contrasta em relação ao todo.

Unificação: consiste na igualdade ou semelhança dos estímulos produzidos pelo objeto, sendo identificada a partir da presença de harmonia, equilíbrio, ordem visual e coerência de linguagem ou estilo.

Fechamento: refere-se à capacidade de agrupar elementos que parecem se completar, formando unidades.

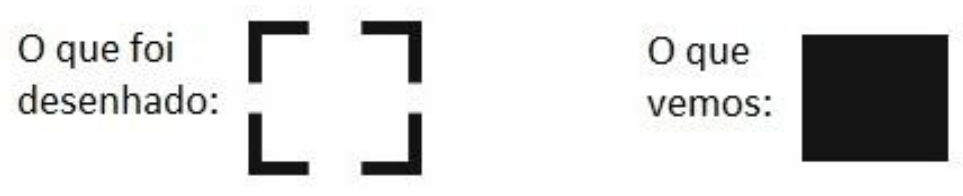

Figura 11: Lei de fechamento

Fonte: Design.blog, 2009 
Continuidade: de acordo com a forma que os elementos estão dispostos, dão a impressão visual de continuidade suave, sem barreiras ou interrupções, formando um trajeto suave único.
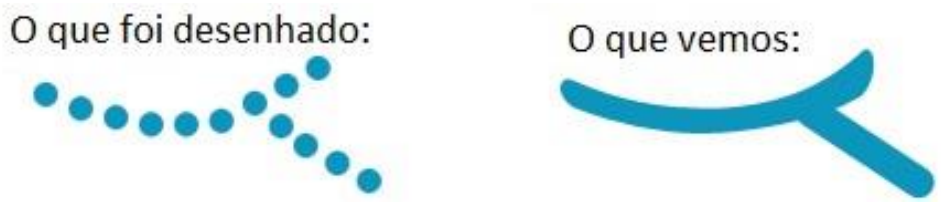

Figura 12: Lei da continuidade

Fonte: Design.blog, 2009

Proximidade: elementos agrupados de acordo com a distância entre os mesmos. Quanto mais próximos, tendem a ser percebidos agrupados.

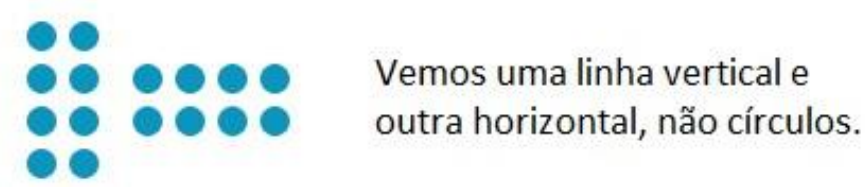

Figura 13: Lei da proximidade

Fonte: Design.blog, 2009

Semelhança: quando os elementos apresentam forma ou cor similar, tendem a ser unificados.

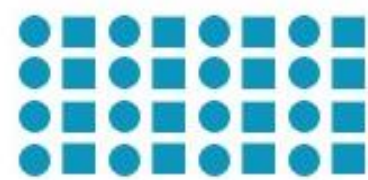

Vemos colunas verticais e não círculos e quadrados.

Figura 14: Lei da semelhança

Fonte: Design.blog, 2009 
Pregnância da Forma: ou lei da simplicidade, determina que os elementos, quanto mais simples a sua forma se apresenta, mais facilmente são assimilados.
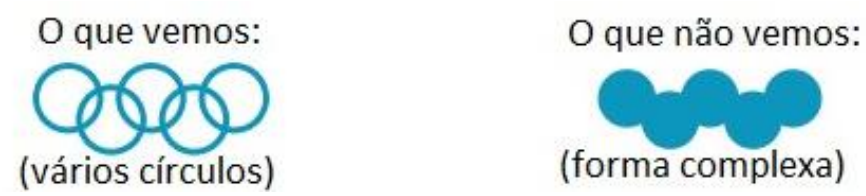

Figura 15: Lei da simplicidade

Fonte: Design.blog, 2009

Vernon (1974) afirma que os psicólogos gestaltistas consideram que a percepção do ambiente ocorre principalmente pela forma, ou seja, um ambiente homogêneo pode não ser percebido ou parecer vago, sem localização no espaço. A percepção só ocorre na medida em que surge alguma forma ou padrão e na medida em que são discriminados em virtude do contorno que os separa de seu fundo: o método de figura-fundo é aspecto primário e fundamental para a percepção.

Em síntese, a teoria é bastante complexa e aponta inúmeras maneiras de se trabalhar com as questões perceptivas, sendo que seu uso pode ser empregado tanto na edificação, quanto na sua elaboração dos espaços internos, utilizando recursos de figura-fundo, contrastes de cor, de direção e de luz e sombra, etc.

É necessário compreender o espaço como algo que vai além da construção física. A percepção do espaço físico não somente passa por múltiplos sentidos, mas registra múltiplos estímulos ao mesmo tempo, entretanto dificilmente, responde-se ou se é atingido por apenas um aspecto deste ambiente físico, mas por sua Gestalt (GÜNTHER, 2003).

\section{Considerações finais}

A arquitetura, mais do que uma profissão, ou forma de arte é também produto cultural, tendo em vista que partindo dela são definidas características de civilizações, que estão diretamente ligadas aos aspectos culturais e históricos. À medida que o homem vai evoluindo, a arquitetura acompanha este processo, adaptando-se as necessidades daquele, possibilitando grandes modificações estéticas, formais e funcionais aos edifícios, desde os primórdios até a arquitetura contemporânea. 
Sob a ótica da arquitetura como forma de arte pode-se afirmar que esta é capaz de transmitir emoções através do uso correto das formas. Tais sentimentos, assim como as demais formas de arte, transparecem e revelam as intenções do arquiteto - artista, enquanto os usuários e observadores percebem, ainda que de forma inconsciente, estas emoções, como afirma a teoria da empatia.

A proposta de iniciar questionamentos relativos à relação da psicologia aliada à arquitetura e da relação da psicologia ambiental e o espaço tem como objetivo fazer com que haja o entendimento da importância do pensar um espaço para as pessoas, levando em consideração que as formas e a disposição de elementos interferem diretamente no comportamento e no cotidiano dos indivíduos, bem como no bem estar e na qualidade dos ambientes de toda edificação.

\section{Referências}

BENUTTI, Maria Antonia. A geometria das catedrais góticas e neogóticas. UNESP FAAC, Departamento de Artes e Representação Gráfica. São Paulo, 2011. Disponível em: < http://www.graphica.org.br/CD/PDFs/EPIST/EPIST01.pdf >, acesso em 14/01/2018.

COLIN, Silvio. Uma introdução à arquitetura. Rio de Janeiro: Uapê, 2000.

FILHO, João Gomes. Gestalt do objeto: sistema de leitura visual da forma. São Paulo: Escrituras, 2004.

FISCHER, Ernst. A necessidade da arte. Tradução: Leandro Konder. Rio de Janeiro: Guanabara, 1987.

GÜNTHER, Hartmut. Mobilidade e affordance como cerne dos Estudos PessoaAmbiente. Estud. psicol. (Natal). maio/ago. 2003, vol.8, no.2.

KOFFKA, Kurt. Princípios de Psicologia da Gestalt. São Paulo: Cultrix, 1975.

MARTAU, Betina T. A arquitetura multisensorial de Juhani Pallasmaa. Arquitetura Revista. Rio Grande do Sul, v. 3 p. 56-58, jul./dez. 2007.

MICHAELIS. Dicionário online. Disponível em: < http://michaelis.uol.com.br/moderno/portugues/index.php?lingua=portuguesportugues\&palavra=empatia $>$, acesso em 09/06/2012. 
PINHEIRO, José Q. Psicologia Ambiental: a busca de um ambiente melhor. Estud. psicol. (Natal). jul/dez. 1997, vol.2, no.2.

RIVLIN, Leanne G. Olhando o passado e o futuro: revendo pressupostos sobre as interrelações pessoa-ambiente. Estud. psicol. (Natal). maio/ago. 2003, vol.8, no.2.

STRICKLAND, Carol. Arquitetura Comentada: uma breve viagem pela história da arquitetura. Rio de Janeiro: Ediouro, 2003.

ZEVI, Bruno. Saber ver a arquitetura. São Paulo: Martins Fontes, 2002.

\section{Como citar este artigo (Formato ABNT):}

DALLASTRA, Mauricio; OGURA, Caroline; GAZZONI, Bruna; BRESCOVIT, Luiz Eduardo; COSTA, Bruna Lopes. Psicologia e arquitetura: como a Einfühlung e a gestalt atuam nos ambientes. Id on Line Revista Multidisciplinar e de Psicologia, 2018, vol.12, n.39, p.658-673. ISSN: 1981-1179.

Recebido: 19.01.2018

Aceito: 24.01 .2018 